\title{
The dichotomy that faces nursing tutorial staff
}

\author{
Andrea M. Corbett \\ Western Institute of Technology at Taranaki, School of Nursing, New Plymouth, New Zealand. \\ Email: a.corbett@witt.ac.nz
}

Received 27 May 2011; revised 18 June 2011; accepted 27 June 2011.

\begin{abstract}
There is a requirement for tutorial staff teaching on a degree programme to be engaged in research activity on a continuing basis. This is often in conflict with the demands that tutors in the Bachelor of Nursing programme are required to have academic ability and clinical skills whilst at the same time, engage in meaningful research activity. This does not occur. A study of the literature finds a commonality of this dichotomy throughout the world. A question is raised as to the impact of the increasing age of the nursing workforce; does this have an impact on the development of a research culture? It is suggested that the joint project approach adopted by the WITT (Western Institute of Technology at Taranaki) School of Nursing will assist in overcoming some of the identified issues and begin the development of a research culture within the School that will be ongoing.
\end{abstract}

Keywords: Nursing Education; Research; Nursing Tutor; Bachelor of Nursing; Research Activity

\section{INTRODUCTION}

The New Zealand Education Act, 1989, requires staff engaged in teaching on a degree programme to be engaged in research activity that is verifiable and subject related. There are allowances made for a progression in the development of a research culture from:

Staff not engaged in research, but engaged in research-informed study and qualifications upgrading, therefore being able to offer teaching that is in-formed by recent research and inspired by research knowledge;

Staff conducting research as a major component of study towards a higher degree;

Staff engaged in qualification independent research.

The (New Zealand) Education Act 1989 (3) states: The Authority shall not consent to the granting of an award that is described as a degree unless it is satisfied that the award recognises the completition of a course of advanced learning that -
1) Is taught mainly by people engaged in research; and

2) Emphasises the general principles and basic knowledge as the basis for self-directed work and learning.

It is pertinent to note that the New Zealand Qualifications Authority (NZQA) does not regard activity mainly concerned with keeping abreast of new developments in subjects as "research". It is assumed by them that providers will as a matter of course en-sure that all teachers of degree courses have sufficient time to keep abreast of new developments both in their subject areas and in methods of teaching and assessment.

The NZQA "Approval and Accreditation of Courses Leading to Degrees and Related Qualifications 2010 Version 4, August 2010 states:

8. Research: The adequacy of provision of research facilities and support of staff involved in research, the levels of research activity of staff involved in the course and of ways by which the research teaching links are made in the curriculum.

Staffs conduct research within their area of experience which advances knowledge and understanding and supports their function as teachers.

The quality and quantity of staff research outputs are monitored and the collective output is consistent with the development and maintenance of an on-going research culture in support of the course.

Organisational systems and facilities provide appropriate support to staff involved in research, including access to an appropriate ethics committee.

This tertiary institute's Quality Management Systems (QMS) state that "research is also recognised as an integral component for academic staff development, in particular staff teaching on degree level programmes.”

In examining the requirement for persons employed in nursing degree programmes to be engaged in research activity along with the requirement that the individual is also proficient in academic and clinical expertise raises a number of issues. Not the least of these is the belief that research and teaching are linked to the extent that productive researchers are good teachers. It is stated by 
Felder (2010) that there is no logical reason to expect productivity in research and effectiveness in teaching to be closely related as they have different goals and require different skills and personal attributes [1].

According to Felder "excellent researchers must be observant, objective, skilled at drawing inferences, and tolerant of ambiguity." Excellent teachers on the other hand are skilled at "communication, familiar with the promotion and establishment of conditions that promote learning, approachable and empathetic." [1] There is also the finding that there is no significant correlation between research productivity and teaching effectiveness are provided. The formatter will need to create these components, incorporating the applicable criteria that follow.

\section{THE LOCAL SITUATION}

The WITT School of Nursing has a staff of 6 persons employed as tutors, a Programme Director and a Head of School. All these persons hold a Masters Degree and one has a doctoral degree. However when an examination is made of the nature of the Masters degrees held by staff only three are considered to have a major component of research activity contained in them for the award to be made. This is not to say the degree is not worthy by being one comprised of 800 level papers, simply that the expectation that because an individual holds a Masters degree they understand and can participate in research activity is erroneous. There would be no dispute that the individual staff members are, or have been, engaged in scholarly activity, however it is also a reality that in fact some of the tutorial staff have no skills or ability to undertake research at even a basic level without guidance and assistance. Some universities and larger institutes of technology now require all staff upgrading or studying towards higher qualifications to have a research methods paper as one of their papers [2]. This is not currently being considered by this institution. As all the staff of this School of Nursing would be categorized as middle aged, the issue of motivation to want to progress higher in qualifications level is an issue that cannot be overlooked.

\subsection{Age}

Reference to the aging of the New Zealand nursing workforce in line with global trends is referred to in the Annual Report of the Nursing Council of New Zealand with $53 \%$ of Registered Nurses actually practicing and issued an Annual Practicing Certificate are over the age of 45 years [3]. If an examination of the practice area related to nursing education is undertaken the figures of those Registered Nurses over the age of 45 years is actually quite frightening with $63 \%$ of the nursing tutor workforce over that age [4].

\subsection{Time}

A major consideration for a lack of research activity referred to in all published articles, is time. Because the teaching load is quite heavy and continuous in all tertiary institutions, staff do not get the time to develop additional skills which include research activity. In fact one is led to believe that confidence in the abilities of these staff to undertake any level of research is seriously lacking. In a review of the literature summarised by Fielder \& Malcolm (2005) it was stated that there was a common agreement across all sectors of academia that time pressures were a major factor when staff engaged in postgraduate study [5]. They identified time release from teaching duties was important for engagement in research. This is also supported in a discussion the development of a research culture at the University of Technology in Jamaica, detailed how reduction in the teaching load was recognised as essential for staff engaged in research [6]. It is important to acknowledge that the WITT School of Nursing staff members made the time to upgrade their degree level qualifications to Masters degree. Where the "time" consideration is often used as the reason these same staff members do not engage in post-Masters scholarly/research activity currently, what is lacking is the will to so engage.

With time constraints and lack of expertise and knowledge there comes a lack of motivation on the part of staff members and the development of raised anxiety levels. This is not assisted by the lack of institutional support for professional development in this area. It is stated that perceptions of value were associated strongly with the support and time release to undertake research activity given by an institution employing the staff member [5]. With the current drive in the New Zealand tertiary sector, driven by Government and implemented by direction of the Tertiary Education Commission (TEC), it would take a bold employer to reduce the staff/student ratio to allow this to happen.

\subsection{Position Demands}

An examination in a study on the interrelationship between time and the demands of the position occupied found that the time teaching, preparing for teaching, and engaging in research activity had all extended the demands on the tutor than was evident in the past [7]. Coupled with this were the tangible commodities of salary, staffing, working conditions, and the resources available to them to accomplish their work which all affected how appreciated and supported by the School and the institution they felt. Over and above resources they indicated that feeling respected by those with whom 
they work was also important. It is also pertinent to this discussion to be aware that in the Annual Workload Plan developed jointly with the staff member and the WITT Head of the Nursing School, time is allocated from the total student class contact hours for research activity. The fact it does not occur is often stated to be because there is no "time" for the staff member to fit it in with their academic and clinical teaching and supervision duties. That is, the staff member does not perceive that they have indeed been allocated any time that is manageable.

\subsection{Stress}

In considering the raised stress levels many staffs state they experience the factors involved in this are at least of two considerations. There is the stress associated with obtaining post graduate qualifications whilst maintaining academic and clinical excellence, along with running a home and family responsibilities many have [8]. This of course is exacerbated with the age of the teacher - the older the nurse gets the more likely they are to have family, home and other commitments that take priority in planning their lives. However in this report we are examining the factors that lead those tutors with post graduate qualifications (i.e. Masters degrees) to speak of stress in undertaking research activity. There is a stress associated with the dichotomy of the requirements of teaching and research activity. It was Ackerlind (1999) who stated that academics are highly motivated and they possess a driving force to engage with all academic activities to maintain professionalism [9]. Do these same academics not see the importance of research activity as part of this professionalism? Ackerlind does not think so and the author of this commentary would agree.

\section{WHERE TO FROM HERE?}

In examining the issue of staff undertaking research activity in conjunction with the academic and clinical requirements of their position we need to start with the fact that whilst espoused in the Institute's QMS there is a low cultural environment in the institution associated with research. The nature of research is appreciated and research outputs are carefully recorded and published in the Annual Report of the institution with pride. Whilst these activities may indeed add to the stature of the institution it is questionable whether the contributions of those engaged in research are significantly valued by the institution. Whilst the Education Act requires it, an audit by the NCNZ or ITPQ would find the School of Nursing degree programme to be seriously wanting in staff actively engaged in research activity.

In examining the issue it was first acknowledged that most of the staff that held Masters degrees qualifications had obtained their degrees by obtaining a progression of papers, one of which may have been a dissertation; however they had not actually engaged in research activity in any meaningful depth. In an endeavour to improve this knowledge gap the Head of School and the Research Co-coordinator developed a plan for a research study that would involve all staff members taking a role and contributing to a single study. The hope was that, with guidance, these staff members' contribution would add up to a complete whole and the output for the year would be a study worthy of consideration in the nursing and health milieu. This concept was believed to be a way forward in building up the motivation for research activity among the staff. This activity is progressing.

\section{CONCLUSIONS}

From a study of the available and pertinent literature, and with personal discussions with Val Keating, Principal lecturer in Nursing at the Sheffield Hallam University, it would appear that the dichotomy and demands of academic and clinical excellence coupled with the requirement to undertake research activity are almost unsolvable. The nursing tutorial workforce reflects international trends by being an aging work-force. This makes the integration of research activity into their daily work role more difficult. We would argue though that the dichotomy is not a problem but a challenge that faces us. It would appear that there needs to be more emphasis placed on enhancing re-sources and providing research mentorship to champion research activity within the Institution and the School of Nursing. The current joint study project as outlined may well go a long way to meeting some of these goals. It may offer other Schools of Nursing a way forward.

\section{REFERENCES}

[1] Felder, R.M. (2010) The link between research and teaching. How to strengthen each without weakening the other. Chemical Engineering Education, 44, 213-214.

[2] New Zealand Ministry of Education. (2002) Report of the performance-based research fund working group. Investing in Excellence, Wellington.

[3] Nursing Council of New Zealand, (2010a) Annual Report to year ended 31 March, 2010. Wellington.

[4] Nursing Council of New Zealand. (2010b) The New Zealand Nursing Workforce. Wellington

[5] Fielder, K. and Malcolm, P. (2005) Aligning academic activities: Implications for teaching and research in a New Zealand Institute of Technology. Systemic practice and action research, 18, 275-301.

doi:10.1007/s11213-005-4815-8

[6] Onyefulu, C.C. and Ogunrinade, A.F. (2005) Kick starting research in newly emergent universities: Why faculty do not apply for research development 'seed' funding at the University of Technology Jamaica. Journal of Re- 
search Administration, 36, 56-65.

[7] Wimsatt, L., Trice, A. and Langley, D. (2009) Faculty perspectives on academic work and administrative bur-den: Implications for the design of effective support ser-vices. Journal of Research Administration, 40, 71-88

[8] May, D. (1997) Planning time in working for a doctorate.
In: Graves, N. and Varma, V. Eds., Working for a doctorate. Routledge, London.

[9] Ackerlind, G.S. (1999) Growing and developing as an academic: What does it mean? Herdsa 1999 Conference, Melbourne, 12-15 July 1999. 